\title{
Sobre la equidad contractual y la obligatoriedad del vínculo: Una mirada a la luz de la protección jurídica del contratante débil
}

\author{
On Contractual Fairness and the Bindingness of the Contractual Bond: \\ An Analysis in Light of the Legal Protection of the Weaker Contracting \\ Party
}

\author{
RENZO MUNITA MARAMBIO*
}

\begin{abstract}
Resumen
La equidad contractual y el rol de la voluntad en la obligatoriedad del acuerdo obligacional, permiten ser considerados como elementos esenciales en el cometido de argumentar jurídicamente, que en el derecho civil de las obligaciones, es posible detectar herramientas suficientes en el sentido de proteger al contratante que se sitúa en una posición de debilidad frente al otro. En este entender, no resulta indispensable estar revestido de la calidad de consumidor para aspirar a la mencionada tutela; toda vez que aquella puede desprenderse de particulares nociones que nuestro ordenamiento jurídico permite integrar. En este ejercicio destacan las modernas lecturas de la confianza legítima y del equilibrio contractual, las cuales bajo una corporeidad diversa a la buena fe, son susceptibles de ser inspiradas en el criterio del favor debilis, el cual para nosotros resulta fundamental en la definición de la línea directriz del presente trabajo.
\end{abstract}

Palabras clave: Autonomía de la voluntad; ley de contrato; obligatoriedad; equidad; contratante débil; favor debilis.

\begin{abstract}
Contractual fairness and the will's role on the bindingness of contracts can be regarded as essential elements for the task of juridically argument that it is possible to find enough tools within the law of obligations to protect the contracting party that is in a weak position with respect to the other. In this sense, it is not necessary to have the status of a consumer to be entitled to the aforementioned protection, since such regime can be articulated from particular notions integrated to our legal system. In this framework, the modern interpretation of legitimate trust and contractual equilibrium are stressed. These notions can be inspired by the favor debilis criterion rather than the notion of good faith. This criterion is fundamental to define the directive line of this work.
\end{abstract}

Key words: Free will; contract law; bindingness; fairness; weaker contracting party; favor debilis.

* Universidad del Desarrollo, Chile (renzomunita@udd.cl). Artículo presentado en las XVII Jornadas Nacionales de Derecho Givil, el 4 de octubre de 2019 en la Universidad Adolfo Ibáñez, Viña del Mar. 


\section{NOTAS PRELIMINARES}

Lo que pretendemos poner en relieve en este trabajo dice relación con que el derecho civil de las obligaciones puede significar una herramienta efectiva en la protección de la parte más débil de vínculos contractuales no gobernados por el derecho del consumo. La idea que subyace es que no es necesario estar investido de la calidad de consumidor, para ser tutelado por el derecho, pudiendo también un no consumidor ser objeto de resguardo, aunque por normas diversas del estatuto consumerista. En rigor, tal como señala Momberg, "la noción de consumidor como parte débil a proteger en las relaciones de mercado, ha sido superada por la constatación que existen otras categorías de sujetos que se encuentran en una situación similar al consumidor y que por tanto merecen igual (o mayor) protección". ${ }^{1}$

El ejercicio no es antojadizo, pues es posible percibir un interés similar en comentados instrumentos de soft law, que en nuestro entender son capaces de reflejar los lineamientos principales del moderno derecho de los contratos desde perspectivas globales. ${ }^{2}$ En síntesis, el reconocimiento que en justicia se le ha atribuido al derecho del consumo como modelo corrector de asimetrías ${ }^{3}$ no debe provocar una invisibilidad del derecho civil en el mismo cometido, máxime si se percibe en términos de Maume una "mutación de la atmósfera contractual", ${ }^{4}$ capaz de suspender en su órbita el reconocimiento de nuevas figuras, dentro de ellas: la parte débil.

Para atribuir corporeidad a la denominada parte débil no necesariamente debemos visualizar hipótesis rebuscadas, ya que, por ejemplo, podemos pensar en empresas de menor tamaño, y en particular en micro y pequeñas empresas (desde el prisma de la Ley $\mathrm{N}^{\circ} 20.416$ de 2010), que se vinculan en calidad de proveedoras con grandes empresas, debiendo aceptar las condiciones, a veces desproporcionadas, que estas les imponen. Un abuso en el poder negociador, entonces, corresponde a una imagen bastante concreta del objeto de estas líneas.

Así las cosas, en palabras de Carbonnier "el derecho va más allá que una regla de derecho", 5 y como tal, no solo quienes dispongan a su favor de un entramado más o menos orgánico de normas de resguardo (como el que significa la Ley № 19.496 de 1997) pueden ser objeto de amparo jurídico. Estimar lo contrario, según enseña Mazeaud, "significaría satisfacer una protección selectiva y discriminatoria, toda vez que las mismas causas no producirían los mismos efectos". ${ }^{6}$ En síntesis, creemos que quien debe ser protegido es el jurídicamente débil, con independencia de su calificación, propósito que el citado Momberg estima que debiera conseguirse a través de "una regulación general que vaya más allá de

\footnotetext{
${ }^{1}$ Momberg (2015), p. 749.

${ }^{2}$ Así lo advierte López (2019b).

${ }^{3}$ Cf. Morales y Mendoza (2019); Isler (2019b).

4 Maume (2015), p. 8.

${ }^{5}$ Carbonnier (2001), p. 21.

${ }^{6}$ Mazeaud (1998), p. 95.
} 
reacciones puntuales por medio de la dictación de normativa específica". ${ }^{7}$ Por su parte, no necesariamente la protección de la que hablamos debe su acento a las sanciones que son susceptibles de ser impuestas a quien vulnera los intereses del débil, pues siguiendo a López, el foco debe apuntar hacia la "tutela de aquel que merece protección [...] ponderando los intereses en conflicto y alcanzando una solución más justa". ${ }^{8}$

\section{PLAN}

Por lo anterior, cabe cuestionarnos si es que resulta necesario que el estatuto civilista moderno, o si se prefiere, integrativo del débil, sea orgánicamente definido a través de figuras jurídicas recogidas por vía de reforma al Código Civil [al estilo de países de tradición codificada como Francia que ha sido protagonista de un proceso de actualización ${ }^{9}$ incorporando formalmente el deber de información (art. 1112-1), ${ }^{10}$ contratos de adhesión (art. 1110), ${ }^{11}$ cláusulas abusivas entre no consumidores (art. 1171)], ${ }^{12}$ o si bien este puede desprenderse de las mismas normas que nuestro texto general ya contiene [aquello podría explicar, por ejemplo, que nuestra jurisprudencia nacional haya extendido el deber de información desde la órbita precontractual en razón de una justa interpretación del artículo $1546,{ }^{13}$ aunque haya sido reacia a sancionar favorablemente la imprevisión]. ${ }^{14}$

Si bien el ejercicio sistematizador que supone una reforma es útil, entendemos que ella no es indispensable para configurar la tutela referida, de aquí que la equidad contractual reflejo del favor debilis pueda ser entendida como una efectiva herramienta protectora. A su

\footnotetext{
${ }^{7}$ Momberg (2015), p. 749.

${ }^{8}$ LOPEZ (2019a), p. 158.

${ }^{9}$ Ordenanza N²016-131 de 2016, ratificada por la Ley N²018-287 de 2018.

10 Article 1112-1: Celle des parties qui connaît une information dont l'importance est déterminante pour le consentement de l'autre doit l'en informer dès lors que, légitimement, cette dernière ignore cette information ou fait confiance à son cocontractant.

Néanmoins, ce devoir d'information ne porte pas sur l'estimation de la valeur de la prestation.

Ont une importance déterminante les informations qui ont un lien direct et nécessaire avec le contenu du contrat ou la qualité des parties.

Il incombe à celui qui prétend qu'une information lui était due de prouver que l'autre partie la lui devait, à charge pour cette autre partie de prouver qu'elle l'a fournie.

Les parties ne peuvent ni limiter, ni exclure ce devoir.

Outre la responsabilité de celui qui en était tenu, le manquement à ce devoir d'information peut entraîner l'annulation du contrat dans les conditions prévues aux articles 1130 et suivants.

11 Article 1110: Le contrat de gré à gré est celui dont les stipulations sont négociables entre les parties.

Le contrat d'adhésion est celui qui comporte un ensemble de clauses non négociables, déterminées à l'avance par l'une des parties.

${ }^{12}$ Article 1171: Dans un contrat d'adhésion, toute clause non négociable, déterminée à l'avance par l'une des parties, qui crée un déséquilibre significatif entre les droits et obligations des parties au contrat est réputée non écrite.

L'appréciation du déséquilibre significatif ne porte ni sur l'objet principal du contrat ni sur l'adéquation du prix à la prestation.

${ }^{13}$ Cf. Medina Guajardo Elizabeth contra Hospital Clínico Fusat (2009); Cristóbal Tienken Fernández con Clínica Las Condes S.A. (2015).

14 Por todos, De la MaZA (2011); Momberg (2010).
} 
turno, aun cuando se afirmare que el principio de la autonomía de la voluntad podría verse vulnerado a través del recurso a la equidad contractual en la protección del más débil, creemos que en ocasiones es necesario alterar los parámetros ideológicos que han soportado las clásicas lecturas contractuales. Se refuerza lo que decimos en el debilitamiento del principio de la autonomía de la voluntad, fenómeno que vuelca en la buena fe, en la confianza razonable o en el equilibrio contractual, el corazón de la obligatoriedad del vínculo.

De lo expuesto es posible colegir los dos pilares de nuestra intervención, en una primera parte nos referiremos a la protección del contratante débil desde la perspectiva de la equidad contractual; y en la segunda, nos pronunciaremos respecto de la tutela del vulnerable desde la perspectiva de la obligatoriedad del vínculo.

\section{PROTEGGIÓN DEL GONTRATANTE DÉBIL Y LA EQUIDAD GONTRACTUAL}

En los cimientos de la indicada protección un principio cobra especial relevancia: el favor debitoris. ${ }^{15}$ Castán conceptualizándolo, indica que "responde al deseo de suavizar, en los casos dudosos, la situación de los deudores". ${ }^{16}$ En prueba de lo anterior, no es menor que en algunas legislaciones, como la nuestra, ciertos puntos sean zanjados en su favor, ya sea en razón de un imperativo legal, o como el resultado de un ejercicio supletorio cuando las partes no han abordado clara o equilibradamente la contradicción de fuerzas negociadoras del vínculo. Se protege en definitiva el interés contractual del deudor, y en consecuencia se le permite "liberarse del cumplimiento de la obligación y no ver agravada su posición en el vínculo obligatorio como consecuencia del incumplimiento", en palabras de López. ${ }^{17}$

Entre las manifestaciones en que el Código Civil chileno reconoce el favor al deudor, son varias las que destacan. Por una parte, la regla general del onus probandi en la existencia de la obligación, por cuanto el artículo 1698 lo establece de cargo del acreedor, y algunas clasificaciones de las obligaciones, tales como en las alternativas, así el artículo 1500 ordena que recae en el deudor la alternativa, a falta de estipulación; facultativas, pues el artículo

\footnotetext{
${ }^{15}$ Para un análisis del favor debitoris desde una perspectiva histórica, Cf. ISLER (2019a). La autora se refiere la dimensión que comprendía la obligación en Roma, la cual, si bien se identificaba con elementos de corte patrimonial como extrapatrimonial o indisponibles, aquello posteriormente habría evolucionado y decantado hacia una concepción netamente objetiva. Con todo, AEDO (2013), p. 98, ha manifestado cuestionamientos a esta forma de entender la institución. De hecho, indica que "no se advierte un tránsito marcado del vínculo personal al patrimonial. En el procedimiento de ejecución propio del procedimiento formulario, permanece latente el carácter personal del vínculo: la posibilidad de la venta del íntegro patrimonio del deudor y la nota de infamia son solo ejemplos. En nuestros días tampoco el vínculo se identifica con un ejercicio meramente objetivo o exclusivamente patrimonial, sino que también incorpora elementos de carácter personal vinculados, por ejemplo, al prestigio del obligado o a su reprobación social, piénsese en boletines comerciales, o en registros internos elaborados por instituciones financieras.

16 Castán (1961), p. 835.

17 LÓpez (2012), p. 38.
} 
1505 permite al deudor elegir entre pagar con la cosa debida o con la que se designa; o, como dispone el artículo 1507 al establecer que en caso de duda en la calificación obligacional se reenviará al estatuto de las alternativas; y, desde luego, en la proscripción a la solidaridad sin fuente, a la luz de lo señalado en el artículo 1511 , inciso $2^{\circ}$.

Lo mismo se aprecia en modos de extinguir particulares. En cuanto al pago, el artículo 1574 considera que el deudor no debe reembolsar lo pagado en caso de pago contra de su voluntad; el artículo 1588 fija en el domicilio del deudor el pago de la obligación de una especie o cuerpo cierto, a falta de estipulación; el artículo 1597 faculta al deudor a imputar el pago a la deuda que prefiera cuando no exista diferencia entre deudas devengadas y no devengadas (mismo criterio se desprende igualmente del artículo 1596); el artículo 1595 presume pagados los intereses, en caso de no hacer mención a ellos en la carta de pago; a mayor abundamiento, el mismo el pago por consignación, es concebido precisamente para permitir que el deudor quede liberado, según se desprende del artículo 1598. En materia de remisión, el artículo 1654 admite una forma tácita a través de la cual puede operar el señalado modo de extinguir, contemplándose además que, si bien el acreedor puede manifestar que "no fue hecha con el ánimo de remitir la deuda", resulta necesario que lo pruebe, pues de lo contrario "se entenderá que hubo ánimo de condonarla". Respecto de la pérdida de la cosa debida, el artículo 1680 libera de responsabilidad al deudor cuando la cosa debida se ha destruido en su poder "después que ha sido ofrecida al acreedor, y durante el retardo de éste en recibirla", a menos que se pruebe su culpa grave o dolo.

Mientras que otras expresiones se detectan desde la órbita del derecho de contratos, tanto respecto de la interpretación de los mismos: en este sentido, el artículo 1566 establece una regla supletoria en el ejercicio a favor del deudor, cuando las cláusulas ambiguas no provengan de la falta de explicación del propio obligado; como en cuanto a disposiciones especiales relativas a particulares contratos, tal como revisaremos en los párrafos siguientes.

Así, en la regulación de la compraventa, toda vez que el artículo 1820 libera al deudor en la entrega de la cosa debida - el vendedor- del riesgo de la misma; siendo aquella norma además la concretización para la compraventa del artículo 1550 cuyo objeto de estudio corresponde a la denominada teoría de los riesgos; el artículo 1826, inciso $3^{\circ}$ consagra una especial protección al deudor de la obligación de entregar, en circunstancias que "después del contrato hubiere menguado considerablemente la fortuna del comprador de modo que el vendedor se halle en peligro inminente de perder el precio"; el artículo 1874, en cuyo mérito la cláusula de no transferirse el dominio, o de reserva de propiedad, no impide al comprador - deudor de pagar el precio- de adquirirlo, toda vez que "no producirá otro efecto que el de la demanda alternativa enunciada en el artículo precedente". Por otra parte, en materia del pacto comisorio calificado por no pago del precio, Bello consideró que el comprador - deudor de la obligación de pagar- puede hacer subsistir el contrato pagándolo, "lo más tarde, en las veinticuatro horas subsiguientes a la notificación judicial de la demanda", lo cual supone una excepción al efecto relativo de las estipulaciones, tal como da cuenta el artículo 1879. Mismo criterio se aprecia en el párrafo relativo al pacto de retroventa, así el inciso $2^{\circ}$ del artículo 1885, señala que el comprador -deudor de la obligación de restituir- tiene derecho a que el vendedor le de aviso del ejercicio del mismo, 
estableciéndose además una especial época para la restitución en caso en que la cosa sea fructífera.

Lo propio identificamos en el contexto del mandato, específicamente deteniéndonos en la lectura del artículo 2137 que hace referencia a la delegación a la que ha sido expresamente autorizado el mandatario, designándose por el mandante la persona del delegado. En rigor, si bien el mandatario puede igualmente ejecutar el encargo, también puede delegarlo en dicha persona, constituyendo aquello una obligación alternativa, recayendo en él la elección; optándose por la delegación "se constituye entre el mandante y el delegado un nuevo mandato que sólo puede ser revocado por el mandante, y no se extingue por la muerte u otro accidente que sobrevenga al anterior mandatario"; o del artículo 2158, inciso $2^{\circ}$, que establece una garantía en favor del mandatario -deudor en el cumplimiento del encargo- en cuya virtud, solo la prueba de culpa permite al mandante "dispensarse de cumplir estas obligaciones, alegando que el negocio encomendado al mandatario no ha tenido buen éxito, o que pudo desempeñarse a menos costo". Por último, se le faculta al mandatario, hacer uso de un derecho legal de retención, que recae sobre "los efectos que se le hayan entregado por cuenta del mandante para la seguridad de las prestaciones a que éste fuere obligado por su parte”, según dispone el artículo 2162 del Código Civil.

Desde el análisis de la prenda, a favor del deudor prendario puede mencionarse el inciso $2^{\circ}$ del artículo 2396 que establece que "será oído", en caso en que "pidiere que se le permita reemplazar la prenda por otra sin perjuicio del acreedor", constituyendo esto otra excepción al efecto relativo de los contratos. La tutela se aprecia de igual forma en el artículo 2393, que se refiere al derecho que tiene el deudor de retener la cosa dada en prenda, cuando ésta haya llegado a su poder por cualquier causa, siempre el deudor "pague la totalidad de la deuda para cuya seguridad fue constituida". Ni siguiere puede reclamarla el acreedor que bien podría invocar nuevos créditos "aunque reúnan los requisitos enumerados en el artículo $2401 \%$.

No debería pensarse que necesariamente el deudor debe en todo caso ser entendido como la parte más débil del vínculo, por cuanto en ocasiones es definitivamente la parte más fuerte de aquel. De hecho, en términos de Rogel,

el deudor que -dicho sea de paso y en las relaciones obligatorias sinalagmáticas, que son las más numerosas- lo es porque antes fue acreedor y vio enteramente satisfecho su crédito. El deudor, contrato mediante, no es siempre, ni mucho menos, la parte más débil de este. Como acreedor, puede haber impuesto sus condiciones en él, puede haber establecido que la prestación a que tiene derecho - casa vendida, libros impresos- le sea entregada inmediatamente, quedando el deudor de una contraprestación que no ha cumplido aún e, incluso, no tiene prisa por cumplir, aun pudiendo hacerlo. ${ }^{18}$

Sin ir más lejos, la doctrina nacional se ha preocupado considerablemente de la situación del acreedor cuando se ve expuesto al incumplimiento obligacional total o parcial,

${ }^{18}$ Rogel (2010), p. 128. 
estudiando las acciones o remedios que el derecho le asiste, sobre los cuales se reconoce la existencia de un derecho de opción a favor del acreedor. ${ }^{19}$

Con todo, también pueden ser desprendidas del Código de Bello algunas manifestaciones concretas relativas a la protección del acreedor. A modo ejemplar, esto se aprecia en la hipoteca en razón a que el artículo 2427 se refiere a los derechos que puede impetrar el acreedor, en caso en que "la finca se perdiere o deteriorare en términos de no ser suficiente para la seguridad de la deuda"; en la garantía que significa pactar obligaciones genéricas, pues el tenor del artículo 1508 advierte una concretización de la máxima latina genera non pereunt; e igualmente en el modo de extinguir pérdida de la cosa debida, ya que el artículo 1677 ordena que aun cuando la cosa perezca sin culpa del deudor, extinguiéndose por lo tanto su obligación, el acreedor "podrá exigir el acreedor que se le cedan los derechos o acciones que tenga el deudor contra aquellos por cuyo hecho o culpa haya perecido la cosa".

Las disposiciones antes presentadas no las entendemos como normas de excepción, sino más bien como expresiones formales de equidad contractual en diversos pasajes del Código Civil, sea fijando en el deudor la condición de sujeto titular de una especial protección, y representándolo como la parte más débil del vínculo, cuestión que no excluye en ningún caso que el vulnerable pueda ser el acreedor. De aquí que el favor debitoris, bajo una lectura amplia, pueda concebirse, en palabras de Castán, y en primer lugar, como "un adagio fundado en consideraciones de equidad"; ${ }^{20}$ que, en segundo lugar, fuerza salir de sus fronteras semánticamente reduccionistas, para concebir el favor debilis que para nosotros adquiere el carácter de supraprincipio (luego explicaremos el porqué de esta calificación) con vocación a intervenir en el moderno derecho de los contratos, en el cometido de proteger a quien se ve expuesto a condiciones contractuales injustas, cualquiera sea su posición en el vínculo.

Lo indicado nos parece relevante, toda vez que como expusimos, no es necesario recurrir a reformas para integrar este supraprincipio, por lo expuesto la protección, siguiendo nuevamente a Momberg, "debería entenderse aplicable a todos los casos y para todas las partes que lo requieran, exista o no norma específica que asî lo señale". ${ }^{21}$ La misma percepción puede entenderse en la defensa que cierta doctrina autorizada formula, al proponer una serie de alternativas de que dispondría el contratante débil para defenderse de las prestaciones originariamente justas, pero sobrevenidamente injustas, ${ }^{22}$ cuyo cumplimiento le es exigido; así puede recurrir al capítulo de la nulidad absoluta, relativa,

19 Cf. Elgueta (1981), p. 110; Pizarro (2006), pp. 247 y ss.; Vidal (2007), p. 59; Pizarro (2008), p. 397; ABELIUK (2010), pp. 529 y ss.; CORRAL (2010), pp. 231 y ss.; LÓPEZ (2012), pp. 16 y ss.

${ }^{20}$ CASTÁN (1961), p. 848.

${ }^{21}$ Momberg (2015), p. 753.

${ }^{22}$ Integramos en la reflexión la distinción entre desequilibrio originario y sobrevenido, propuesto por LÓPEZ (2015a), p. 132. 
indemnización de daños, ${ }^{23}$ además de la posibilidad de promover la adaptación del contrato. ${ }^{24}$

\section{PROTEGGIÓN DEL GONTRATANTE DÉBIL Y LA OBLIGATORIEDAD DEL CONTRATO}

El panorama expuesto en la primera parte, adquiere mayor fuerza desde la perspectiva de la falta de una real justificación del principio de la autonomía de la voluntad como soporte de la obligatoriedad del acuerdo, la cual, en nuestro concepto, más bien debe circunscribirse al afán de justicia que debe evidenciar un contrato, ya que no siempre "quien dice contractual, dice justo", ${ }^{25}$ así como que la entidad de las prestaciones no es siempre irrelevante. Reflejo de lo mencionado, resulta la convicción de que la equidad contractual, alma del favor debilis, no debe desentenderse de su propósito más íntimo: la persecución de la justicia contractual, ${ }^{26}$ la cual López afirma que se logra "asegurando a las partes una relación igualitaria que se traduzca en la proporcionalidad de sus prestaciones". ${ }^{27}$

Es por lo dicho que, aun cuando una postura tradicional sostenga lo contrario, ${ }^{28}$ parece cuestionable que sea la autonomía de la voluntad el principio que permita, por sí mismo y en sí mismo, explicar la obligatoriedad del contrato, en otros términos, afirmar que la voluntad se basta a sí misma;"29 de hecho, Pizarro sostiene que "la voluntad de las partes constituye un elemento fundamental para la formación del contrato, mas carece de fuerza explicativa de su obligatoriedad. La voluntad de las partes determina, en principio, el contenido obligacional, esto es, las obligaciones que deberán cumplir los contratantes, pero no puede explicar el carácter obligatorio del contrato". ${ }^{30}$ En el mismo sentido, Corral, quien manifiesta: "Una absolutización ideológica del principio de la intangibilidad contractual, que llevara a excluir a priori todo tipo de intervención en el contenido de un acuerdo contractual, correría un serio riesgo de transformar el contrato en un instrumento de explotación y dominio más que de expresión de la libertad personal";31 y Pereira, que, por su parte, argumenta:

Las dimensiones que identifican el ámbito contractual contemporáneo se encuentran asociadas a una disminución de la influencia de la autónoma voluntad

\footnotetext{
${ }^{23}$ LÓPEZ (2019b).

${ }^{24}$ LÓPEZ (2018).

25 Cf. comentando la expresión de Fouillée, Cf. Rolland (2006), p. 769.

${ }^{26}$ Cf. DE LA MAZA (2007), pp. 571 y ss.; PIZARro (2011), pp. 7 y ss.

27 LÓPEz (2015a), p. 126.

${ }^{28}$ Cf. Somarriva (1934), pp. 17 y ss.; CORRaL (2018), pp. 495 y ss.

${ }^{29}$ Cf. López y ElORRiaga (2017), p. 247.

30 PizARro (2004), p. 236.

${ }^{31}$ Corral (2010), p. 292.
} 
de las partes, como criterio de justificación para el efecto obligatorio del contrato y, consecuencialmente, un incremento de la intervención heterónoma del legislador en la celebración o configuración de los vínculos contractuales. De modo que la autonomía de la voluntad pudiere resultar obstaculizada si se pretende afirmarla como la justificación normativa de la fuerza obligatoria del contrato. Se puede pensar que la voluntad ya no es el prisma bajo el cual se afirma la regla contractual, así como sostener que si lo fuere de igual manera, no puede reconocérsela como $e l$ fundamento irrestricto según el cual se admitió en la moderna teoría del contrato. ${ }^{32}$

Lo antes señalado, va en línea con lo que ha defendido la profesora Gómez en España, quien refiriéndose a la obligatoriedad en la ejecución de las prestaciones, y sin desconocer el rol de la libertad contractual como impulsor del vínculo, ${ }^{33}$ señala que no es impensable que aquel pueda resultar en definitiva desequilibrado y en consecuencia no obligatorio. ${ }^{34}$ El discurso de la citada autora persigue cuestionar la ortodoxia en la lectura de los principios de libertad contractual y de respeto a lo pactado, que reflejamente provoca que los jueces carezcan de facultades para controlar el resultado de los contratos, pudiendo exclusivamente concentrarse en el proceso de contratación. Lo anterior, desde el postulado relativo a que "[L]a libertad contractual garantizaría la justicia interna del contrato". ${ }^{35}$ En esencia se reprocha que el derecho de contratos no pueda hacerse cargo de injusticias sustantivas o de contenido, debiendo excluyentemente ocuparse de aspectos más bien propios a injusticias de corte procedimental o de gestación del acuerdo, que en otras palabras significa aplicar el estatuto de los vicios del consentimiento.

Pues bien, no siempre las circunstancias del nacimiento del contrato permitirán que el contratante más débil sea sujeto de protección por dicho estatuto - el de los viciosconstituyendo aquello el quid del asunto. Gómez a propósito de este punto, enseña:

lo que ocurre en los casos que aquí interesan es que la posición de debilidad de uno de los contratantes afecta a su libertad contractual, de modo que consiente el contrato que es sustantivamente injusto, o bien forzado por las circunstancias (por su propio estado de necesidad o dependencia o por la situación de poder del cocontratante, que no le deja elección), o bien sin ser enteramente consciente del compromiso asumido (por limitación de sus capacidades, falta de conocimiento o experiencia o por su posición de confianza respecto del otro contratante). La falta de libertad o la falta de consciencia nos sitúa en un escenario similar al de clásicos vicios del consentimiento como el dolo, la violencia o la intimidación. Y, aunque en las hipótesis de abuso que ahora nos ocupan no tiene por qué haber una abierta

\footnotetext{
32 Pereira (2016), p. 74.

${ }^{34}$ GÓMEZ (2018), pp. 19 y ss.

35 GÓMEZ (2018), p. 23.
}

${ }^{33} \mathrm{E}$ incluso con anterioridad a él; el asunto ha sido objeto del análisis por doctrina nacional a propósito del cumplimiento del deber de informar en la esfera precontractual, confirmándose con ello la interpretación amplia que debe asignarse al artículo 1546 del Código Civil. Cf. BoETSCH (2011), pp. 140 y s.; DE LA MAZA (2010a), p. 28 (el autor desarrolla la aplicación del principio desde la perspectiva de la racionalidad imperfecta); CAORSI (2016), p. 24; DE LA MAZA (2008), pp. 43-72; DE LA MAZA (2009), p. 48; DE LA MAZA (2010b), p. 79; DomíngueZ (2012), p. 56; Munita (2019). 
conducta ilícita del que explota la vulnerabilidad ajena, sí cabe hacerle a este un serio reproche desde el momento en que esa explotación es consciente y se traduce en la obtención de una ventaja injusta o desproporcionada. ${ }^{36}$

En nuestro entender, lo expuesto revela la dimensión del problema jurídico objeto del presente análisis. No existen técnicamente vicios en la voluntad, sino que circunstancias que provocaron desigualdad sustantiva, aun cuando no formal.

Una manifestación en este ámbito podemos detectarla en la sentencia de la Corte Suprema Ingenierias y movimientos de tierras Tranex Ltda. Con Anglo American Sur S.A. ${ }^{37}$ En los hechos, se suscribió entre las partes un acuerdo contractual de movimiento de tierras, pactándose una cláusula de conveniencia, en cuya virtud, Anglo American S.A. se reservaba la facultad para poner término al contrato "sin indicación de causa". Aconteció, que invocándose como motivo la pérdida de la confianza en el contratista, efectivamente se puso fin a la relación contractual. Tal como se lee en la sentencia que referimos, la decisión de la empresa requirente de los servicios,

se asiló en el principio del pacta sunt servanda para argüir que la terminación anticipada del contrato operó conforme a derecho pues la facultad que ejerció encuentra origen en un acuerdo válido de un claro tenor, sujetando estrictamente su decisión a los requisitos establecidos en esa cláusula cuyo ejercicio no da derecho a indemnización o compensación de ninguna especie, sin perjuicio del pago de los servicios efectivamente prestados hasta la fecha de término anticipado (c. 13).

En definitiva, la Corte Suprema rechazó el recurso de casación en el fondo, confirmando el fallo del tribunal de alzada respectivo, que ordenó la compensación de Tranex. En el razonamiento, el tribunal recuerda que el artículo 1546 del Código Civil debe ser interpretado desde su proyección como un imperativo de lealtad que reposa en los "los contratantes el deber de comportarse correcta y lealmente en sus relaciones mutuas, desde el inicio de los tratos preliminares y hasta momento incluso ulteriores a la celebración del contrato", ${ }^{38}$ según afirman López y Elorriaga, que, constituyendo el corazón de la buena fe objetiva 39 "debe ser mirada como elemento integrador de los contratos y, concebida de ese modo, sirve de basamento al deber de garantía que asumen los contratantes” (c. 27).

En efecto, no debiera ser interpretado inflexiblemente un acuerdo contractual, cuando el recurso a la cláusula de conveniencia suponga una vulneración al principio de buena fe. La Corte cita un fallo de la Corte de Apelaciones de Pedro Aguirre Cerda (4 de marzo de 1988, R.D.J., T. 85, secc. 2, pág. 9) para fundamentar la anterior; en dicha sentencia se lee: "Ninguno de los contratantes debe asilarse en su literalidad inflexible para

\footnotetext{
36 GÓMEZ (2018), p. 23.

37 Ingenierías y movimientos de tierras Tranex Ltda. Con Anglo American Sur S.A (2019).

38 LÓPEZ y ElORRiaga (2017), p. 435.

39 Tal como expone doctrina autorizada, la aproximación objetiva de la figura es a la que se "está remitiendo el artículo 1546 del Código Civil cuando prescribe que los contratos deben ejecutarse de buena fe, y que, de consiguiente, los contratos no sólo obligan a que en ellos se expresa" (LÓPEZ y ELORRIAGA (2017), p. 434).
} 
dar menos ni para exigir más, arbitrariamente, al influjo de un interés propio y mezquino; antes bien, debe dejarse expresar al contrato ampliamente su contenido. Ni debe dejarse de atender a factores extraliteralidad que pudieran fundarse en la naturaleza del pacto, en la costumbre o en la ley" (c. 27).

Es por lo indicado que, el acuerdo, aun sin vicios, de una cláusula de terminación unilateral, no debe ser invocada arbitraria o infundadamente. La buena fe impregna también el desenlace de los vínculos contractuales, cuestión que se opone diametralmente a la aplicación caprichosa de cláusulas como la que se comenta. En síntesis, "la buena fe que debía orientar el obrar de la demandada durante la ejecución del contrato le exigía justificar las razones que le permitían terminar anticipadamente ese contrato" (c. 28), lo que en autos no fue demostrado. Nos parece acertada dicha consideración.

De otro lado, la buena fe, consideramos, no debiera ser confundida con el principio de la confianza legítima que pudiere ser invocado en la protección del vulnerable a título de una concretización del favor debilis. Técnicamente hablando el principio de la confianza legítima, tal como señala López, es más amplio que la buena fe, ya que "no solo obedece exclusivamente a consideraciones morales o subjetivas, sino también económicas o utilitaristas, excediéndola y desbordándola, y encontrando su fundamento, más que en la obligación del emisor de la declaración de actuar leal y correctamente, en el hecho de que su actuación ha generado expectativas razonables en su destinatario que deben ser tuteladas, porque existió una apariencia que determinó el surgimiento de una confianza digna de protección", ${ }^{40}$ dotándolo además de funcionalidad independiente, pues persigue "proteger las expectativas legitimas del contratante diligente, propósitos que no pueden alcanzarse recurriendo a la buena fe". ${ }^{41}$

La sentencia anteriormente citada también se pronuncia respecto de la protección de las válidas expectativas de la parte débil; y si bien lo hace desde una aproximación terminológica cercana a la buena fe, en lo sustantivo entendemos que la argumentación debe incorporarse como una concretización del principio de la confianza legítima, toda vez que el supuesto - que ya revisaremos- solo limitadamente o confusamente, en nuestro entender, puede leerse desde la lógica del cumplimiento de un deber de colaboración recíproca, tal como lo formula la misma sentencia (así en el considerando 30).

En la especie, la sentencia declara: "Anglo [...] infringió su deber de ejecutar de buena fe el contrato por su conducta que creó una apariencia de que la relación con Tranex se mantenía dentro de los márgenes de confianza" (c. 29). Lo ordenado se entiende, pues tal como se desprende de autos, Anglo no obstante haber adquirido la convicción de no perseverar en el contrato, no tan solo nada comunicó a Tranex, sino que además creó un escenario de normalidad que configuró un espíritu de confianza en la demandante, proponiéndole incluso una reforma contractual un mes antes de manifestar su decisión de no perseverar. A su turno, nada comunicó respecto del sobrecosto en las obras que significó para la contratista la no implementación de un sistema de transporte bimodal, estando Anglo

\footnotetext{
${ }^{40}$ LÓPEZ (2019a), p. 157.

${ }^{41}$ LÓPEZ (2019a), p. 157.
} 
obligado a ello. La segunda vulneración a la confianza legítima de Tranex se manifiesta, pues tal como señala el fallo: "frente a los requerimientos de pago por los sobrecostos que se originaron justamente por esa falta de implementación no los rechazó expresamente, como lo imponía el artículo 1546 del Código Civil, sino que mantuvo silencio y, entretanto, los servicios siguieron realizándose" (c. 33). De ahí que se considerara que los elementos de juicio en mención, permitieran a la Corte Suprema juzgar el supuesto como un caso de silencio circunstanciado (c. 33).

En el derecho francés se ha explorado igualmente el indicado principio al cual se le ha entendido como un criterio efectivo en la determinación de obligaciones contractuales, como de delimitación de las mismas.

En cuanto a la determinación, no debe entenderse unida a la voluntad del deudor el fundamento de la obligación del vendedor de entregar la cosa, sino que más bien a la confianza que el cumplimiento de dicha obligación suscita en el comprador. Dudezert explica el principio de la confianza legítima a la luz de la obligación de seguridad a cargo del transportista, la que debe verificarse a lo largo de todo el trayecto y que al ser de naturaleza contractual tiene por fuente la promesa del deudor. ${ }^{42}$ Nos resulta interesante lo mencionado, por cuanto tal como comenta López: "recurrir a la buena fe como fundamento de un determinado instituto resulta vago e impreciso, toda vez que su progresiva expansión y utilización por la doctrina la ha convertido en una "cláusula general" o "norma abierta", cuyo contenido abstracto solo adquiere una significación concreta en cada una de las figuras en que el deber de lealtad, rectitud y corrección que ella evoca se manifiesta" ${ }^{43}$ aspectos que tributan asimismo, a juicio de los Principios latinoamericanos de Derecho de los Contratos, en su carácter "amplio e inasible". 44

En cuanto a la delimitación, se emplea el principio a propósito de la distinción entre obligaciones de medio y de resultado. En este sentido, si la naturaleza de la obligación permite suponer al juez que el resultado podría no conseguirse si aún actuando diligentemente puede intervenir un alea, el acreedor no podría entonces invocar la confianza legítima frente al incumplimiento de la obligación; ${ }^{45}$ así, por ejemplo, respecto de la obligación del médico de intervenir quirúrgicamente; en contra, el principio si pudiera ser invocado, en cuanto a la obligación del abogado de presentar el recurso oportunamente. Con todo, no debe desatenderse que si el contrato obliga es precisamente porque es justo y no exclusivamente porque las partes lo hayan acordado autónomamente. En concordancia con aquello, se ubica el principio del equilibrio contractual, el cual para López se respeta "cuando pueda constatarse la existencia de prestaciones cualitativamente recíprocas o conmutativas y que sean, a la vez, cuantitativamente equivalentes o proporcionadas", ${ }^{46}$ cuestión que explica, que para los citados Principios latinoamericanos de Derecho de los

\footnotetext{
${ }^{42}$ Cf. Dudezert (2017), p. 140.

${ }^{43}$ LÓPEZ (2015b), p. 117.

${ }^{44}$ DE LA MAZA et al (2017), p. 24.

${ }^{45}$ Cf. Dudezert (2017), p. 142.

${ }^{46}$ LÓPEZ (2015b), p. 127.
} 
Contratos, un contrato "no merece ser obligatorio, dado el desequilibrio que proporciona a un contratante la ventaja desmedida frente al otro". ${ }^{47}$

\section{NOTAS FINALES}

La protección por el contratante débil constituye el afán primordial de este trabajo. La referida tutela logra su justificación jurídica en el supraprincipio del favor debilis, reflejo de la equidad que debe inspirar los vínculos contractuales. El reconocimiento de dicho favor, no requiere de una reforma particular (aun cuando sería de utilidad), pues éste puede inferirse de la lectura de diversos pasajes del Código Civil. Por otra parte, el recurso a la equidad contractual va en la línea de aclarar porqué el contrato obliga, llegándose a la convicción que lo hace porque es justo. En este espacio, resulta conveniente reflexionar sobre los principios que nacidos al alero del favor debilis (de aquí que sea un supraprincipio), permiten responder técnicamente cuándo un contrato dispone de dicha calidad. Así, puede decirse que no es justo cuando tras el incumplimiento hay buena fe de parte del infractor de la regla del contrato (piénsese en la imprevisión), o que si lo es, ya sea cuando es legítima la confianza del acreedor en la ejecución de la obligación (piénsese en el deber de seguridad), o cuando el vínculo es equilibrado (en cuyo marco se ha propuesto incluso una lectura general en el recurso a la lesión enorme)..$^{48}$ En fin, estimamos que las alternativas mencionadas constituyen poderosas herramientas pretorianas en el cometido de visualizar soluciones a situaciones de afectación de los intereses del contratante desmejorado.

${ }^{47}$ DE LA MAZA et al (2017), p. 24.

${ }^{48}$ Cf. LÓPEZ (2015b). 


\section{BIBLIOGRAFÍA GITADA}

Abeliuk Manasevic, René (2010), Las obligaciones, tomo I (5a ed., Editorial Jurídica de Chile).

Aedo Barrena, Cristian (2013). "Obligatio in iure consistum", Revista Chilena de Derecho, Vol. 40, No 3, pp. 953-988.

Boetsch GiLlet, Cristián (2011). La buena fe contractual (Editorial Jurídica de Chile).

CAORsi LeÑERO, Oscar (2016). "La obligación de informar en el derecho privado chileno", Memoria para obtener el grado de Licenciado en Ciencias Jurídicas (Facultad de Derecho, Universidad de Chile).

Carbonnier, Jean (2001). Flexible droit. Pour une sociologie du droit sans rigueur (10ème éd, LGDJ).

Castán VÁzQUeZ, José (1961). "El favor debitoris en el derecho español", Anuario de Derecho Civil, Vol. 14, No 4, pp. 835-850.

Corral Talaiani, Hernán (2010). Contratos y daños por incumplimiento (Abeledo Perrot LegalPublishing).

Corral Talciani, Hernán (2018). Curso de Derecho Civil. Parte General (Thomson Reuters).

DE LA MAZA GAZMURI, Iñigo (2007). "Justicia contractual, contratos por adhesión electrónicos y buena fe", en CorRaL TALGiani, Hernán \& RodríGuEz PINTO, María Sara (eds.). Estudios de Derecho Civil II (Editorial Lexis Nexis), pp. 571-592.

DE lA MAZA GAZMURI, Iñigo (2008). "Buena Fe, el reverso de la moneda. A propósito del dolo por omisión y el deber precontractual de informar”, Revista Chilena de Derecho Privado, $\mathrm{N}^{\mathrm{o}} 11$, pp. 43-72.

DE la MAZA GaZMURI, Iñigo (2009). Los limites del deber precontractual de información, Tesis doctoral, Universidad Autónoma de Madrid.

DE LA MAZA GAZMURI, Iñigo (2010a). "El suministro de información como técnica de protección de los consumidores: los deberes precontractuales de información”, Revista de Derecho Universidad Católica del Norte, Vol. 17, N², pp. 21-52

DE LA MAZA GAZMURI, Iñigo (2010b). "Tipicidad y atipicidad de los deberes precontractuales de información", Revista de derecho, Universidad de Valparaíso, № 34, pp. 75-99.

DE LA MAZA GAZMURI, Iñigo (2011). "Las consecuencias de la alteración sobrevenida de las circunstancias", en FigueroA YáÑEZ, Gonzalo; Barros Bourie, Enrique \& TAPIA Rodríguez, Mauricio (eds.), Estudios de Derecho Civil VI (Abeledo Perrot, Thomson Reuters).

DE la MaZa Gazmuri, Iñigo et al. (2017). Principios latinoamericanos de Derecho de los Contratos (BOE).

Domínguez Águila, Ramón (2012). Teoría general del negocio jurídico (Editorial Jurídica de Chile). 
Dudezert, Franck (2017). De l'existence d'un principe de confiance légitime en droit privé. Thèse, Université de la Rochelle.

Elgueta Anguita, Augusto (1981). Resolución de contratos y excepción de pago (Editorial Jurídica de Chile).

Gómez Calle, Esther (2018). Desequilibrio contractual y tutela del contratante débil (Aranzadi Thomson Reuters).

ISLER SOTO, Erika (2019a). "Del favor debilis al favor consumatore", Revista de Derecho PUCP, $\mathrm{N}^{\circ}$ 82, pp. 35-59.

ISLER SotO, Erika (2019b). Derecho del consumo. Nociones fundamentales (Tirant Lo Blanch).

LÓPEZ DíAZ, Patricia (2012). "El abuso del derecho de opción del acreedor y su importancia en la construcción de un sistema equilibrado de remedios por incumplimiento contractual", Revista Chilena de Derecho Privado, N 19, pp. 13-62.

LÓPEz DÍAz, Patricia (2015a). "El principio de equilibrio contractual en el Código Civil chileno y su particular importancia como fundamento de algunas instituciones del moderno derecho de las obligaciones en la dogmática nacional", Revista Chilena de Derecho Privado, No 25, pp.115-181.

LÓPEZ DíAZ, Patricia (2015b). "Por una noción amplia de lesión enorme en el Código Civil Chileno: una relectura a partir del principio de equilibrio contractual y la idea de excesiva desproporción contenida en el borrador de los Principios Latinoamericanos de Derecho de los Contratos", en VIDAL, Álvaro; Severín, Gonzalo \& MejÍAs, Claudia (eds.), Estudios de Derecho Civil X (Thomson Reuters).

LÓPEZ DíAZ, Patricia (2018). "La adaptación del contrato como medio de tutela precontractual en el Código Civil chileno", Revista de Derecho de la Universidad Austral, vol. 31, $\mathrm{N}^{\mathrm{o}} 1$, pp. 127-157.

LóPEz DÍAZ, Patricia (2019a). "La confianza razonable y su relevancia como criterio fundante de la tutela de ciertas anomalías o disconformidades acaecidas durante el iter contractual: una aproximación desde la doctrina y la jurisprudencia chilenas", Revista de Derecho Privado, № 36, pp. 127-168.

LÓPEZ DíAZ, Patricia (2019b). "El desequilibrio contractual y la tutela del contratante débil: una aproximación desde el derecho civil chileno y la ley 19.496 sobre protección de los derechos de los consumidores". Ponencia aprobada para ser presentada en II Jornadas nacionales de Profesoras de Derecho Privado.

López Santa María, Jorge y Elorriaga De Bonis, Fabián (2017). Los Contratos, Parte General (6th ed., Thomson Reuters).

MAUME, Florian (2015). Essai critique sur la protection du consentement de la partie faible en matière contractuelle, Thèse, Université d'Evry-Val-d' Essonne.

MAZEAUD, Denis (1998). "Droit du marché et droit commun des obligations", RTD com. p. 95. 
Momberg URIBE, Rodrigo (2010). "La revisión del contrato por las partes: el deber de renegociación como efecto de la excesiva onerosidad sobreviniente", Revista Chilena de Derecho, Vol. 37, $\mathrm{N}^{\circ}$ 1, pp. 43-72.

Momberg Uribe, Rodrigo (2015). "Análisis de los modelos de vinculación del Código Civil y la legislación de protección al consumidor. Hacia un principio general de la protección de la parte débil en el derecho privado", Revista Chilena de Derecho, vol. 43, № 2, pp. 737756.

Morales Ortiz, María Elisa y Mendoza Alonzo, Pamela (eds.) (2019). Derecho del consumo: Ley, doctrina y jurisprudencia (Der Ediciones).

Munita Marambio, Renzo (2019). "Reflexiones en torno al deber precontractual de informar y su formalismo típico", en Temas actuales de Derecho Patrimonial (Thomson Reuters).

PEREIRA FREDES, Esteban (2016). ¿Por qué obligan los contratos? Justificación normativa de la obligatoriedad del vínculo contractual (Thomson Reuters).

Pizarro Wilson, Carlos (2004). "Notas críticas sobre el fundamento de la fuerza obligatoria del contrato. Fuentes e interpretación del artículo 1545 del Código Civil Chileno”, Revista Chilena de Derecho, Vol. 31, N², pp. 225-237.

Pizarro Wilson, Carlos (2006). "Las cláusulas resolutorias en el Derecho Civil chileno", Cuadernos de Actualización Furídica, Vol. III (Ediciones de la Universidad Diego Portales).

Pizarro Wilson, Carlos (2008). "Hacia un sistema de remedios al incumplimiento contractual", en GuZmán BRITO, Alejandro (ed.), Estudios de Derecho Civil III (LegalPublishing).

Pizarro Wilson, Carlos (2011). "Notas sobre arbitraje, equidad y justicia contractual". Gaceta furídica, No 370.

Rogel VIDAL, Carlos (2010). Favor debitoris, Análisis crítico (Reus).

Rolland, Louise (2006) "'Qui dit contractuel, dit juste' (Fouillée) ... en trois petits bonds, à reculons", Mcgill Law Journal / Revue de Droit de Mcgill, Vol. 51.

SOMARRIVA UnDURRAGA, Manuel (1934). "Algunas consideraciones sobre el principio de la autonomía de la voluntad", Revista de Derecho y Jurisprudencia, T. 31.

Vidal Olivares, Álvaro (2007). "Cumplimiento e incumplimiento contractual en el Código Civil. Una perspectiva más realista”, Revista Chilena de Derecho, Vol. 34, Nº 1, pp. 41-59. 


\section{JURISPRUDENGIA GITADA}

\section{Chile:}

Corte de Apelaciones de Pedro Aguirre Cerda, 4 de marzo de 1988, Revista de Derecho y Jurisprudencia., T. 85, secc. 2, pág. 9.

Medina Guajardo Elizabeth contra Hospital Clínico Fusat (2009): Corte de Apelaciones de Rancagua, 28 de agosto de 2009 (acción de protección), Rol 625-2009, CL/JUR/1959/2009.

Cristóbal Tienken Fernández con Clínica Las Condes S.A. (2015): Corte de Apelaciones de Santiago, 18 de junio de 2015 (recurso de apelación), Rol 5396-2014, CL/JUR/3423/2015.

Ingenierías y movimientos de tierras Tranex Ltda. Con Anglo American Sur S.A. (2019): Corte Suprema, 22 de mayo de 2019 (Recurso de casación en el fondo y en la forma), Rol 38.506-2017.

\section{NORMAS GITADAS}

\section{Ghile:}

Código Civil de Chile.

Ley $\mathrm{N}^{\circ}$ 20.416, Fija normas especiales para las empresas de menor tamaño. Diario Oficial, 3 de febrero de 2010.

Ley N 19.496, Normas sobre Protección de los Derechos de los Consumidores. Diario Oficial, 7 de marzo de 1997.

\section{Francia:}

Código Civil de Francia.

Ley No 2018-287, ratifiant l'ordonnance n²016-131 du 10 février 2016 portant réforme du droit des contrats, du régime général et de la preuve des obligations. FORF núm. 93, 20 de abril de 2018.

Ordenanza No 2016-131, portant réforme du droit des contrats, du régime général et de la preuve des obligations. Fournal officiel de la République française, JORF, núm. 35, 10 de febrero de 2016. 